\title{
A educação ambiental na teoria educativa Freireana
}

Environmental education in educational theory of freire

\author{
Claudete Robalos da Cruz'; Cláudia Battestin² ; Gomercindo Ghiggi \\ ' Doutoranda em Educação pelo Programa de Pós graduação em Educação da Universidade Federal de Pelotas - UFPel - RS - Brasil \\ 2 Doutoranda em Educação pelo Programa de Pós graduação em Educação da Universidade Federal de Pelotas - UFPel - RS - Brasil \\ ${ }^{3}$ Professor do Programa de Pós Graduação em Educação pela Universidade Federal de Pelotas - UFPel - RS - Brasil
}

\section{Resumo}

O presente artigo tem objetivo de apresentar contribuições da teoria educativa freireana para pensar o processo de formação de professores e a prática da transversalidade no âmbito da educação ambiental. Para tanto tem como referencial teórico, a teoria educativa de Paulo Freire, embora ele não tenha escrito diretamente sobre a temática, educação ambiental, é possível identificar na sua obra elementos que servem como instrumentos conceituais para pensar a educação ambiental numa perspectiva crítica na atualidade.

Palavras-chave: Meio ambiente, Educação, Ética, Paulo Freire.

\begin{abstract}
The objective of this article is to present the contributions of Freireana Theory of Education to reflect on the training process of teachers and the practice of transversalidade in the area of environmental education. To this end the theoy Education, by Paulo Freire, is used as a frame of reference. Although he didn't write espicifically about the topic - environmental education -, one can find elements in his theory that serve as conceptual tools to look at environmental education in a critical way today.
\end{abstract}

Keywords: Environment, Education, Ethics, Paulo Freire. 


\section{INTRODUÇÃO}

Diante de um contexto em que a produção do conhecimento está geralmente pautada num paradigma clássico de pensar, o qual ignora a complexidade da realidade, resultando numa educação acrítica. A educação ambiental emerge numa tentativa de interligar saberes, e romper com paradigmas tradicionais, uma vez que, busca a compreensão da totalidade social no contexto das problemáticas ambientais. Assim, ao mesmo tempo em que a crise ambiental se agrava, tomando esta como crise social, cultural, ecológica, educacional e global, surge uma tentativa de reverter esse quadro. A educação ambiental passa a ser um caminho, não como adestramento ambiental, mas como uma educação que procura novos valores, modos de se viver que possam constituir uma cultura contra-hegemônica. Paulo Freire além de desenvolver um sistema de ensino e aprendizagem, ele nos fornece ferramentas intelectuais para compreendermos o mundo, a partir da sua leitura. Ele nos fornece elementos para uma educação crítica, uma educação engajada com os desafios do seu tempo. Além disso, sua história de vida é um testemunho de uma vida dedicada a construir uma cultura crítica, um mundo mais justo, mais humano, e ecologicamente sustentável.

No livro À sombra desta mangueira, Freire explicita uma visão de mundo cercado de valores, construindo caminhos entre os cheiros, lembranças, memórias, lugares e sabores. Nesta obra, Freire expressa essa comunhão profunda com a natureza e com as lembranças da sua infância. Apresenta também, a importância de uma unificação entre o sentimento e amorosidade durante todo processo de conhecimento e diálogo. É a presença de uma dialética da vida, tão nordestina e tão mundializada, onde o educador conseguiu descobrir o mundo sem deixar de ser pernambucano. É nesta obra que Freire fala da importância que as árvores tiveram na sua infância, principalmente a sombra da enorme e refrescante mangueira: "Sombra e luz, céu azul, horizonte fundo e amplo dizem de mim. Sem eles apenas sobrevivo, menos do que existo" (2006, p. 16).

Durante o período em que Freire ficou exilado, não poucas vezes surgiram memórias acerca das sombras das árvores de sua infância. No inverno chileno, Freire observava como as pessoas que andavam nas ruas procuravam o sol para se aquecer, ao contrário de sua busca pelas sombras, sem ao menos perceber: "no fundo a memória tropical da sombra é que me levava ao lado som- breado. Por isso, lá chegando, voltava, quase num pulo, para a luz" (2006, p. 15). A mesma experiência ocorreu quando Freire foi à África, mas lá o calor era intenso e a resignificação das memórias das sombras de sua infância surgiam como um reencontro e um recriar através da identidade que ocorria a cada momento. E hoje, quais sombras nós procuramos para pensarmos os problemas de nosso tempo? Os problemas ambientais?

\section{RESIGNIFICAÇÃO DAS MEMÓRIAS}

Paulo Freire lembra um passado histórico através das vivencias do presente. "Minha biblioteca de adulto tem algo disso. Às vezes, é como se fosse a sombra da mangueira de minha infância" (2006, p. 16). Essa resignificação de memórias abre caminhos e possibilidades para que o ser humano possa relembrar as lembranças de um passado para tornar o presente mais harmonioso ${ }^{1}$.

Freire sempre demonstrou tamanho afeto pela natureza, principalmente pelas árvores de sua infância. "As frondes arredondadas, a variedade do seu verde, a sombra aconchegante, o cheiro das flores, os frutos, a ondulação dos galhos, mais intensa ou menos intensa em função de sua resistência ao vento" (2006, p. 15). Freire nomeia o quintal de sua casa como o seu primeiro mundo, como um espaço dotado de percepção, sensibilidade e aprendizagem.

O quintal de minha infância vem como se desdobrando em tantos outros espaços, não necessariamente outros quintais. Sítios em que este homem de hoje, vendo em si aquele menino de ontem, aprende por ver melhor o antes visto. Rever o antes visto quase sempre implica ver ângulos não percebidos. A leitura posterior do mundo pode constituir-se de forma mais crítica, menos ingênua, mais rigorosa. Aquele quintal foi a minha imediata objetividade, foi o primeiro não eu geográfico (FREIRE, 2006, p. 24).

A possibilidade de poder relembrar o passado e poder agir radicalmente e com criticidade em relação a algo que pode vir a ser melhor no presente, é um ato de determinação e persistência. Freire (2006) vislumbrava o amanhã com esperança, com pessoas solidárias, justas e comprometidas com a construção de um mundo melhor. Para

1 Uma vez que, a partir do momento que o ser humano desenvolve uma sensibilidade e afeto com a vida, abre precedentes para um cuidado com o todo, envolvendo a biosfera na sua magnitude. 
Freire, não basta estarmos "no" mundo, temos que estar relacionados de forma permanente "com" o mundo, somente assim saberemos da importância em nos reconhecermos como sujeitos históricos.

Não podemos renunciar à luta pelo exercício de nossa capacidade e de nosso direito de decidir e de romper, sem o que não reinventamos o mundo. Neste sentido em que a História é possibilidade e não determinismo. Somos seres condicionados, mas não determinados. É impossível entender a História como tempo de possibilidade se não reconhecermos o ser humano como ser da decisão, da ruptura. Sem esse exercício não há como falarmos em ética (FREIRE, 2006, p. 23).

O ser humano tem possibilidades de reconhecer-se enquanto sujeito de decisões e de possibilidades, mas para isso, é preciso reinventar o mundo e reconhecer-se enquanto sujeito histórico. Ter esse reconhecimento implica estar integrado e reconhecido em uma sociedade, iniciando pela convivência familiar, passando pela escola, pelas experiências de vida e pelas escolhas a serem feitas em nossas relações. Freire deixa claro sobre a importância que os caminhos percorridos tiveram em sua vida, relatando da seguinte forma:

Antes de tornar-me um cidadão do mundo, fui e sou um cidadão do Recife, a que cheguei a partir de meu quintal, no bairro de casa amarela. Quanto mais enraizado na minha localidade, tanto mais possibilidades tenho de me espraiar, me mundializar. Ninguém se torna local a partir do universal. $\mathrm{O}$ caminho existencial é inverso. Eu não sou antes brasileiro para depois ser recifense. Sou primeiro recifense, pernambucano, nordestino. Depois, brasileiro, latino-americano, gente do mundo. Por isso é que, no exílio, minha saudade fundamental não era exclusiva a saudade do Recife; incluía a do meu quintal (FREIRE, 2006, p. 25).

Freire se tornou um verdadeiro cidadão do mundo, pois reconheceu a importância de todas as suas trajetórias, vivências e espaços, sempre valorizando sua trajetória com uma profunda relação de respeito pelos caminhos percorridos. Freire valorizou e respeitou sua história de vida, partindo do princípio de que o ato de educar deveria ocorrer através da realidade e da cultura dos educandos, proporcionando assim uma prática educativa dentro do contexto real vivido. Freire afirma que, "ontem como hoje, jamais aceitei que a prática educativa devesse ater-se apenas à leitura da palavra, à leitura do texto, mas também à leitura do contexto, à leitura do mundo" (2006, p. 30).

Cabe a nos educadores, refletirmos sobre as propostas e planejamentos que poderão ser possíveis e compartilhadas no processo de ensino e aprendizagem. Paulo Freire sempre enfatizou em suas falas a importância da busca constante pelo saber, pela pesquisa e acima de tudo, ter determinação para abraçar qualquer causa que venha a ser abordada em questões de ensino. "Não há palavra verdadeira que não seja práxis. Daí que dizer a palavra verdadeira seja transformar o mundo" (FREIRE, 1980, p. 77).

O educador Pedro Georgen argumenta que: "As novas gerações devem ser familiarizadas com as tradições ético-morais para, num processo racional, discursivo internalizarem aqueles princípios que resultarem desse processo como convenientes para a comunidade" (2001, p. 80). Dentro dessa perspectiva, seria possível assegurar um processo de ensino aprendizagem com uma educação que possa apontar para os perigos e os caminhos que a humanidade deverá seguir. O educador desempenha um papel fundamental tanto na prática como na teoria, pois é através de seus conhecimentos e ensinamentos que poderemos propagar e vivenciar valores acerca da cidadania, responsabilidade e princípios éticos morais.

Educar para o meio ambiente é um dos caminhos para o nosso tempo, para o tempo de necessidades, de emergências e de buscas ${ }^{2}$, devendo ser um processo contínuo, interrupto, em que os ensinamentos sejam de forma dialética, onde todos aprendem e ensinam visando um conhecimento que possa firmar atitudes e desafios. Isso tudo pode não parecer novo, porém, é necessário enfatizar a todo o momento a necessidade de educar com responsabilidade.

Paulo Freire deixa claro em seus últimos escritos o quanto os assuntos ambientais devem estar presentes nas práticas educativas. "A ecologia ganha uma importância fundamental neste fim de século. Ela tem de estar presente em qualquer prática educativa de caráter radical, critico ou libertador" (FREIRE, 2000. p.31). Da mesma forma, "trata-se, em síntese, de saber vincular os problemas ambientais e suas soluções com a vida cotidiana e com a busca daquelas relações harmônicas que nos levem a uma melhoria da qualidade 2 Estamos diante de um desafio: o de saber fazer escolhas a fim de saber decidir e discernir o momento e a maneira de experenciar o mundo. 
de vida" (GUTIÉRESS \& PRADO 2002.p.32).

Educar é preciso, pois visa um processo de reflexão dentro de uma sociedade que está em constante transformação. Um exemplo de transformação global é a crise ambiental que vivemos nesse início de século, causando um verdadeiro impacto na sociedade ${ }^{3}$. A escola tem uma responsabilidade fundamental neste processo de transformação. Não criando uma disciplina que aborde questões sobre meio ambiente e cidadania, mas que esteja presente transversalmente ao longo de todo o currículo.

O livro Ecopedagogia e cidadania planetária (2002) apresenta a possibilidade de ensinar sobre a cidadania ambiental e sustentabilidade a partir de um processo pedagógico. Para que isso ocorra, é necessário compreender e promover a aprendizagem a partir da vida, do cotidiano, afim de que se possa ensinar e aprender resgatando a sensibilidade, a intuição, as emoções, as alegrias, o amor e a satisfação. Sendo assim:

O sentido de trabalhar por um meio ambiente sadio constrói-se num fazer diário, numa relação grupal e pessoal e, por isso, a tomada de consciência ambiental só pode traduzir-se em ação efetiva quando segue acompanhada de uma população organizada e preparada para conhecer, entender e exigir seus direitos e exercer suas responsabilidades (GUTIÉRREZ \& PRADO, 2002, p.14).

Para compreender a crise ambiental que vivemos, é necessário exercer o papel de cidadão crítico na permanente insistência de entender, exigir e lutar para organizar mudanças com bases sólidas na construção de uma sociedade ativa com representações atuantes na participação social ${ }^{4}$. Paulo Freire acreditava que seria possível compreender a situação da sociedade desde que cada ser atuasse a favor de num mundo melhor, mais fraterno e igualitário.

\footnotetext{
3 A crise ambiental que vivemos é uma crise de valores, uma crise da razão, que faz ou deveria fazer com que nós enquanto seres racionais refletíssemos sobre o que representa ser um ser humano em tempos de crise e de emergência.

4 A tarefa e os caminhos a serem seguidos são longos e persistentes. E é neste emaranhado de certezas e incertezas é que nasce, a cada dia uma nova esperança, em lugares diferentes, com pessoas diferentes, mas com realidades de vidas em comum.
}

\section{CONTRIBUIÇÕES FREIREANAS NOS PRESSUPOSTOS ÉTICOS EM SUA TEORIA}

Podemos afirmar que nesta segunda década do século XXI, a humanidade tem presenciado ou vivenciado um momento diferente das outras décadas. O ser humano vive um momento de mudanças, rupturas, momento de reflexão sobre as "dores do mundo", epidemias, crises, inclusive sobre a própria condição humana de agir e pensar. Para Paulo Freire é essencialmente fundamental que o ser humano se reconheça como sujeito de sua própria história. Freire afirma que: "Assumirmonos como sujeitos e objetos da História nos torna seres da decisão, da ruptura. Seres éticos" (2001, p. 40). É fundamental refletirmos sobre as concepções acerca da educação argumentadas por Freire, pois as mesmas possibilitam reconhecer que somente na condição de sujeitos históricos poderemos nos tornar seres éticos. "O que, sobretudo, me move a ser ético é saber que, sendo a educação, por sua própria natureza, diretiva e política, eu devo, sem jamais negar meu sonho ou minha utopia aos educandos, respeitá-los" (FREIRE, 2002, p. 78). Freire defende a universalidade de uma ética nos seguintes termos:

Quando falo, porém, da ética universal do ser humano estou falando da ética enquanto marca da natureza humana enquanto algo absolutamente indispensável à convivência humana. Ao fazê-lo estou advertido das possíveis críticas que, infiéis ao meu pensamento, me apontarão como ingênuo e idealista. Na verdade falo da ética universal do ser humano da mesma forma como falo de sua vocação ontológica para o ser mais, como de sua natureza constituindo-se social e historicamente (FREIRE, 1996, p. 20).

A ética universal é uma práxis coletiva que necessita de sujeitos responsáveis que priorizem a vida, a educação, o respeito, os direitos e os deveres como formas de valorizar e respeitar o ser humano frente aos abusos da civilização tecnológica.

É fundamental que em toda prática e teoria possamos fundamentar os princípios freirianos. Desta forma, poderemos analisar a tarefa educativa não como sendo de responsabilidade exclusiva do ensino formal, mas sim, de todos os sujeitos envolvidos na sociedade. Freire enfatiza também a importância da educação para a diversidade, respeitando as diferentes culturas e realidades 
vividas. $\mathrm{O}$ ato de educar para Freire é um ato de respeito e seriedade, tendo como princípio permanente um agir ético em todas as ações. Freire esclarece a importância da ética na educação da seguinte forma:

Gostaria, por outro lado, de sublinhar a nós mesmos, professores e professoras, a nossa responsabilidade ética no exercício de nossa tarefa docente.(...) Educadores e educandos não podemos, na verdade, escapar à rigorosidade ética. Mas, é preciso deixar claro que a ética de que falo não é a ética menor, restrita, do mercado, que se curva obediente aos interesses do lucro (...) falo da Ética universal dos seres humanos, que condena o cinismo, que condena a exploração da força de trabalho do ser humano (1996, p. 16-17).

Freire acredita que para termos uma formação em que a ética faça parte da sala de aula, entre a relação de educando e educador, é preciso termos uma educação transformadora, conscientizadora e dialógica. O diálogo é essencial e deve ser verdadeiro, transparente e crítico, tanto para quem aprende como para quem ensina, pois isso acarretará em um compromisso e reconhecimento com o próximo.

Para Freire todo ato de ensinar é um caminho difícil, porém válido e prazeroso. Os educadores precisam descobrir e redescobrir a todo o momento a alegria e o prazer em poder ensinar, vivendo intensamente sua prática educativa. A escola precisa saber agir com novos desafios para/ com os educadores, pois a sociedade é multicultural e deve educar o ser humano a fim de despertar sentimentos, respeito e seriedade. É desta forma que percebemos o quanto o ato de educar é sempre um ato ético. A ética está presente, ou deveria estar, em todas as escolhas e decisões realizadas. Neste sentido, é precário o pensamento do professor que vê a ética como uma área do conhecimento afastada da realidade. Neste caso, como poderemos exigir que um professor aborde temáticas ambientais em suas áreas do conhecimento? Primeiramente é preciso reconhecer a importância do ato de educar, englobando a vida como um todo pensando na diversidade, na vida e no futuro dos educandos..

A ética universal possibilita vínculos de interesses coletivos e amplos, na qual poderemos permitir mudanças radicais na sociedade em que vivemos. Mas para que possamos romper com a ideia utilitarista que permeia e condena muitas vezes a nossa sociedade capitalista, precisamos de uma articulação permanente entre educandos e educadores a fim de incumbir uma rigorosidade ética.

A teoria de Paulo Freire continua atualizada para pesquisarmos assuntos emergentes, por exemplo, a educação ambiental. Mas para isso necessitamos pensar na construção de uma ética coletiva que supere o utilitarismo e o antropocentrismo. É importante assumirmos princípios éticos reflexivos a fim de indagar sobre a radicalidade dos problemas, propondo soluções e alternativas sustentáveis para a vida. A educação tem condições de realizar a emancipação dessa racionalidade, proporcionando um processo de ensino-aprendizagem que tenha como princípio ético a responsabilidade.

Para Freire, é possível uma educação ética, desde que todos estejam envolvidos no processo educativo e engajados na luta por uma educação transformadora. O processo de construção do conhecimento se dá quando todos ensinam e aprendem com suas próprias experiências e histórias de vida. Isso tudo levou Freire lutou por uma ética da diversidade, pois a sociedade deve educar o ser humano para a vida, para os valores, a fim de despertar ações e sentimentos que visam proteção e respeito à biosfera ${ }^{5}$.

Além de Paulo Freire assumir com clareza suas opções políticas, pedagógicas e filosóficas, foi reconhecido mundialmente pela sua práxis educativa libertadora, sendo uma referência para a área da educação. Foi a curiosidade pela escrita, pela leitura e pelo mundo, que fizeram Freire apostar na rigorosidade metódica como importante movimento para possibilitar a passagem da curiosidade ingênua à curiosidade epistemológica. Freire argumenta, "A existência, porque humana, não pode ser muda, silenciosa, nem tampouco pode nutrir-se de falsas palavras, mas de palavras verdadeiras, com que os homens transformam o mundo" (1980, p. 92). O ser humano, como existência, não se torna sujeito de investigação, mas como essência, torna-se sujeito capaz de refletir criticamente sobre a sua condição humana.

\footnotetext{
5 Percebemos nos escritos de Freire o quanto suas preocupações visavam um cuidado com as diferentes formas de vida. Isso nos remete a pensar que se Freire estivesse entre nós a luta pela vida continuaria. Seja pela indignação e esperança ou pela ética e responsabilidade.
} 


\section{CONSIDERAÇÕES FINAIS}

Paulo Freire apostou numa educação crítica como instrumento para transformação social. Ele sempre ressaltou a importância da participação nas lutas e movimentos sociais, pois assim vivese a coerência entre o que se diz e o que se faz. Somente através do testemunho através de nossas práticas diárias, é que poderemos construir uma cidadania participativa. É através de uma educação engajada com princípios éticos, responsáveis e coerentes, que o ser humano poderá tornar-se um sujeito consciente e comprometido com as causas emergentes e necessárias para educarmos em tempos de "crise".

A educação ambiental crítica numa perspectiva freireana contribui para repensar os modelos de sociedades que prevalecem como sendo únicos em nosso tempo. Além disso, questiona e busca fortalecer valores radicalmente críticos e éticos no processo de conhecer e processo de viver em sociedade, pois para Freire conhecimento e sociedade se constroem em comunhão com homens e mulheres de seu tempo, conhecimento e sociedade não é um dado da história, uma herança divina trata-se de uma construção cultural humana. Assim que, pensar uma educação para o meio ambiente implica pensar numa construção de valores e de hábitos totalmente radicais. Para finalizar, as célebres palavras de Freire que servem como uma reflexão a ser feita todos os dias enquanto estivermos na luta: "Na compreensão da História como possibilidade, o amanhã é problemático. Para que ele venha é preciso que o construamos mediante a transformação do hoje. Há possibilidades para diferentes amanhãs (...) é preciso reinventar o mundo" (2006, p. 40). E preciso reinventar o mundo, o conhecimento e a nós mesmos, enquanto seres sociais, culturais e ambientais.

\section{REFERÊNCIAS}

ARAÚJO, Ulisses F. Temas transversais e a estratégia de projetos. São Paulo: Moderna, 2003.

BRASIL. Secretaria de Educação Fundamental. Parâmetros curriculares nacionais: terceiro e quarto ciclos: apresentação dos temas transversais / Secretaria de Educação Fundamental. - Brasília : MEC/SEF, 1998.
FREIRE, Paulo. A sombra desta Mangueira. 8 ed. São Paulo: Olho d'Água, 2006.

Pedagogia da esperança: um reencontro com a Pedagogia do oprimido. 9. ed. Rio de Janeiro: Paz e Terra, 2002.

Pedagogia da Indignação: Cartas Pedagógicas e outros escritos. São Paulo: Editora UNESP, 2000 .

Pedagogia da Autonomia: saberes necessários à prática educativa, 30 ed. Rio de Janeiro: Paz e Terra, 1996.

. Pedagogia do Oprimido. 8 ed. Rio de Janeiro: Paz e Terra, 1980.

GADOTTI, M. Educação e poder: introdução à pedagogia do conflito. São Paulo: Cortez, 1988.

GEORGEN, Pedro. Pós-modernidade, ética e educação: polêmicas do nosso tempo. Campinas: Autores associados, 2001.

GUTIÉRREZ, Francisco e PRADO, Cruz. Ecopedagogia e cidadania planetária. São Paulo: Instituto Paulo Freire: Cortez, 2002.

GALLO, S. Transversalidade e educação: pensando uma educação não-disciplinar. In

ALVES N. \& GARCIA, R. L. (Orgs). O sentido da escola. Rio de Janeiro: DP\&A, 1999. 